\title{
EDUCAÇÃO DE JOVENS E ADULTOS: HISTÓRIAS DE VIDA ORAIS DE HOMENS E MULHERES
}

\author{
Izabel Cristina Feijó de Andrade/USJ/UNIPLAC ${ }^{1}$ \\ Wanderlea Pereira Damásio Maurício/USJ ${ }^{1}$
}

\begin{abstract}
RESUMO:
O presente artigo tem como propósito analisar as histórias de vida orais de homens e mulheres da EJA a partir de alguns questionamentos importantes: Quem são essas pessoas que frequentam EJA? O que desejam conquistar? Como vivenciam as dimensões de um currículo multicultural e com a ambientalização curricular? Para essa pesquisa, utilizamos a Pesquisa participante com a inclusão no ano de 2015 de vinte estagiários do curso de Pedagogia do USJ na modalidade EJA, em uma instituição situada no Município de São José/Santa Catarina. Os participantes, além dos 20 alunos do USJ, são duas turmas de EJA composta por 18 alunos com idades entre 16 a 45 anos. A prática pedagógica dos estágios mostrou que as histórias de vida orais dos alunos da EJA estavam repletas de histórias vividas. Dessa forma, consideramos que ao trabalhar com os sujeitos da EJA, devemos também orientá-los para os conhecimentos e mudanças que estão cada vez mais presentes na sociedade, especialmente aquelas relacionadas com a multiculturalidade e a educação ambiental. É importante que nós como professores, abrimos possibilidades de mudança em nossas práticas, para podermos beneficiar os sujeitos que estão presentes na EJA, que buscam formas de estarem inseridos também nas mudanças que acontecem rapidamente na sociedade, e uma delas é retomar as questões relacionadas com a multiculturalidade e a educação ambiental para a sala de aula. Mas, não basta só querer é preciso buscar estratégias de mudanças que possam intervir para mudar e a formar sujeitos críticos.
\end{abstract}

Palavras-chave: Educação de Jovens e Adultos. Multiculturalismo. Histórias de vida Orais. Educação Ambiental.

\section{INTRODUÇÃO}

O presente artigo tem como propósito analisar as histórias de vida orais de homens e mulheres da EJA a partir de alguns questionamentos importantes: Quem são essas pessoas que frequentam EJA? O que desejam conquistar? Como vivenciam as dimensões de um currículo multicultural e com a ambientalização curricular? Nesta pesquisa, optamos pela abordagem qualitativa e utilizamos as histórias de vida orais como instrumento de investigação, visando compreender às significações multiculturais que os alunos da EJA atribuem à suas aprendizagens na área da educação ambiental. Essa pesquisa está vinculada ao Estágio em EJA desenvolvido pelo curso de Pedagogia do USJ que em 2015 enviou vinte estagiários na modalidade EJA para desenvolver a pesquisa: "EJA no contexto dos Estágios do curso de Pedagogia do

USJ: Desafios e Perspectivas" numa instituição situada no Município de São José/Santa Catarina. Os participantes, in locus, foram duas turmas de EJA composta 
por 18 alunos com idades entre 16 a 45 anos. Essa diversidade de interesses e de idades tornaram o ambiente investigado rico e diferente. Para Schwartz (2010, p.13), quando assinala que "as classes da EJA também acolhem [...] sujeitos com nível cultural e educacional diferenciado, o que faz do espaço de sala de aula um ambiente rico e marcado pela diversidade" em que o foco está nas práticas comprometidas com a igualdade, solidariedade, e sustentabilidade:

[...] com base em práticas comprometidas com a construção de sociedades justas e sustentáveis, fundadas nos valores da liberdade, igualdade, solidariedade, democracia, justiça social, responsabilidade, sustentabilidade e educação como direito de todos e todas, são princípios da Educação Ambiental:[...] VI - respeito à pluralidade e à diversidade, seja individual, seja coletiva, étnica, racial, social e cultural, disseminando os direitos de existência e permanência e o valor da multiculturalidade e plurietnicidade do país e do desenvolvimento da cidadania planetária. (BRASIL, 2013, p.550)

As histórias de vida orais revelam a realidade da aprendizagem dos alunos e as vozes dos estagiários da Educação de Jovens e Adultos (EJA), considerando que os contextos social/pessoal/profissional desses dois grupos (alunos da EJA e estagiários), representam suas possibilidades reais de aprendizagens, bem como suas relações com a sala de aula, a educação ambiental e a multiculturalidade. Toda revelação explicitada pelos 18 alunos da EJA e dos 20 estagiários apresentou em seus percursos, uma história, um relato de experiência e uma reflexão.

Ao utilizarmos as histórias de vida orais como instrumento de investigação pudemos perceber como os participantes estão narrando suas experiências e suas aprendizagens, seus percursos de formação e suas histórias de desenvolvimento pessoal e profissional.

Para Mizukami et al. (2002) as histórias de vida orais ou narrativas enquanto estratégia reflexiva e investigativa servem para compreender os processos de aprendizagem, o que vem ao encontro de Monteiro (2003) quando afirma que as histórias de vida orais servem de base para a reflexão e a investigação da compreensão dos processos de desenvolvimento pessoal e profissional. Entendemos que o desenvolvimento pessoal e profissional, resulta de escolhas conscientes voltadas à satisfação das necessidades conscientes e que compõem a história de vida dos sujeitos.

Para Josso (2004, p. 78), as histórias de vida orais, voltadas para o desenvolvimento pessoal e profissional "evidenciam a extrema variabilidade do tempo necessário, das condições psicossomáticas requeridas, dos recursos que estão em jogo e, 
finalmente, dos tipos de resistência ou problemas encontrados [...]". Nesse sentido, homens e mulheres aprendem pelas relações sociais, organizam suas experiências e principalmente formam as histórias de vida orais. Assim criam-se as histórias, as desculpas, as razões para fazer ou não fazer (GALVÃO, 2005).

Analisamos as histórias de vida orais dos investigados e nos deparamos com o conjunto de características que foram compondo o contexto do processo de aprendizagem na Educação de Jovens e Adultos, revelando também as dimensões que compoem o desenvolvimento pessoal e profissional. Concordamos com Mizukami (et al. 2002) quando afirma que esse contexto emerge no instante da história de vida oral, por um motivo especial, que fizeram com que eles fossem lembrados no lugar de outros.

Nesse sentido, analisamos as histórias de vida orais dos alunos da EJA e dos estagiários, confirmando nelas os elementos que justificam nossas teorizações acerca das dimensões multiculturais e ambientais e que nos possibilitam traçar os processos de desenvolvimento pessoal e profissional desses sujeitos.

\section{HOMENS E MULHERES DA EJA: OS ESTAGIÁRIOS EM AÇÃO}

A educação de jovens e adultos - EJA é uma modalidade de ensino que atende educandos que por algum motivo não estudaram ou não completaram em tempo regular o ensino fundamental e médio. Ao falar da EJA é necessário fazer referência a realidade dos educandos: suas histórias de vida e suas especificidades no contexto em que estão inseridos, para então construir uma metodologia que atenda o educando de modo singular. Nas Diretrizes Curriculares Nacionais da Educação Básica (BRASIL, 2013, p. 40) deixa explicitado que:

A instituição da Educação de Jovens e Adultos (EJA) tem sido considerada como instância em que o Brasil procura saldar uma dívida social que tem para com o cidadão que não estudou na idade própria. Destina-se, portanto, aos que se situam na faixa etária superior à considerada própria, no nível de conclusão do Ensino Fundamental e do Ensino Médio.

É bastante encorajador, pensarmos em possibilidade de construir uma nova história, basta que o sujeito da EJA tenha oportunidades e acesso à uma educação de qualidade, o que vai ao encontro do pensamento de Freire (2005, p.8):

Talvez seja este o sentido mais exato da alfabetização: aprender a escrever a sua vida, como autor e como testemunha de sua história, isto é, biografar-se, existenciar-se, historicizar-se. Por isto, a pedagogia de Paulo Freire, sendo método de alfabetização, tem como ideia animadora toda a amplitude 
humana da "educação como prática da liberdade", o que, em regime de dominação, só se pode produzir e desenvolver na dinâmica de uma "pedagogia do oprimido".

Os sujeitos da EJA voltam a estudar para conquistar algo, que sempre sonharam. Percebemos que muitos alunos tinham objetivos para realizar, como ter um emprego melhor ou ter um diploma para fazer faculdade. É o objetivo desejado que os impulsiona a continuar a conquista de um ideal como meta de vida. Isso corrobora com o que Freire sensibiliza o leitor quando destaca que:

Estar no mundo sem fazer história, sem por ela ser feito, sem fazer cultura, sem "tratar" sua própria presença no mundo, sem sonhar, sem cantar, sem musicar, sem pintar, sem cuidar da terra, das águas, sem usar as mãos, sem esculpir, sem filosofar, sem pontos de vista sobre o mundo, sem fazer ciência, sem ensinar, sem ideias de formação, sem politizar não é possível. (FREIRE, 1996, p. 58).

Em concordância com o autor citado, acreditamos que é preciso que o sujeito valorize sua história, narre sua experiência, tomando consciência de sua existência e que sua realidade não o torne inferior a ninguém, e tão pouco seja motivo de vergonha para os que o cerca.

A carência escolar de adultos e jovens que ultrapassaram essa idade tem graus variáveis, desde a total falta de alfabetização, passando pelo analfabetismo funcional, até a incompleta escolarização nas etapas do Ensino Fundamental e do Médio. Essa defasagem educacional mantém e reforça a exclusão social, privando largas parcelas da população ao direito de participar dos bens culturais, de integrar-se na vida produtiva e de exercer sua cidadania. Esse resgate não pode ser tratado emergencialmente, mas, sim, de forma sistemática e continuada, uma vez que jovens e adultos continuam alimentando o contingente com defasagem escolar, seja por não ingressarem na escola, seja por dela se evadirem por múltiplas razões. (BRASIL, 2013. p. 40)

Por terem pouca escolaridade algumas pessoas se sujeitam a fazer trabalhos pesados, recebendo salários que são insuficientes para contribuir com as despesas da casa, tornando sua sobrevivência bastante difícil. Porém é importante ressaltar que nem sempre acontece desta forma com todos os sujeitos da EJA, algumas retomam seus estudos para realizar um desejo pessoal ou para se apropriar de conhecimentos necessários para viver em sociedade.

Registre-se a oportunidade política do Estado brasileiro no sentido de resgatar parte da dívida histórica que possui com adolescentes, jovens e adultos que não possuem escolaridade básica, por meio de normas vitais para 
que sua educação seja compreendida como Direito e, portanto, universal e de qualidade. (BRASIL, 2013, p. 362)

Neste contexto Gadotti (2009, p. 17) nos instiga a fazer uma reflexão:

Quando falamos de eucação já não discutimos se ela é ou não necessária. Parece óbvio, para todos, que ela é necessária para a conquista da liberdade de cada um e o seu exercício da cidadania, para o trabalho, para tornar as pessoas mais autônomas e mais felizes. A educação é necessária para a sobrevivência do ser humano. Para que ele não precise inventar tudo de novo, necessita apropriar-se da cultura, do que a humanidade já produziu. Se isso era importante no passado, hoje é mais decisivo, numa sociedade baseada no conhecimento.

Essa ideia de uma reflexão sobre sua própria história vivenciada na educação emergiu das histórias de vida orais vinculadas ao exercício da docência em EJA dos estagiários do USJ que elencaram pontos fundamentais como: os saberes necessários, o currículo proposto e os sujeitos- alunos da EJA. Com relação às aprendizagens construídas no contexto da EJA, emergem relatos que apresentam as imagens de aulas com as quais esses estagiários trabalharam e perceberam o saber dos alunos da EJA, suas reações, suas expectativas, seus problemas de compreensão, dentre eles destacamos:

[...] é uma pena termos o estágio de EJA somente no final do curso, pois me apaixonei pelos alunos da EJA e acredito que tenho muito a ensiná-los e para aprender sobre essa modalidade de ensino (E1)

Estava com medo de fazer estágio em EJA, mas agora, percebo que é uma modalidade de ensino que precisa de um profissional com formação e dedicação. (E16)

Minha reação foi de admiração pelas pessoas que estavam na EJA. Jovens e idosos compartilhando suas experiências e desejos. (E4)

As turmas de EJA que fiz estágio são maravilhosas, fiz amizades com eles e eles se esforçaram nas minhas aulas . (E4)

Agora, sei o quanto a EJA é importante para a nossa formação. Não podemos infantilizar a EJA, são adultos. Eles têm histórias de vidas que encantam a todos. A experiência vivida, como estagiária, foi muito gratificante e desafiadora, pois sou professora da Educação Infantil. Tenho muito a aprender. (E8)

Assim, as histórias de vida orais dos estagiários pesquisados evidenciam a percepção deles sobre a atuação na EJA e com isso construíram e reconstruíram suas aprendizagens nesse contexto específico. Suas expectativas, suas significações e suas interações são narradas oralmente nas aulas presenciais:

[...] posso considerar que alguns professores da EJA ainda permanece a visão tradicional. O que dificulta a interação entre eles e os alunos. (E 5)

$\mathrm{O}$ que me deu segurança foi a presença do professor regente e da supervisora de estágio durante nossa atuação. Mas, isso ocorreu porque tinhamos afinidade e integração dos trabalhos. (E 9)

O acompanhamento da supervisora faz a diferença. (E19)

O trabalho por projetos torna a prática mais significativa e os resultados são positivos. Todos os alunos da EJA se envolveram com as produções multiculturais e com as pesquisas acerca da Educação Ambiental, tornando o nosso trabalho de estagiário mais significativo. (E 15) 
Percebi um grande número de alunos com dificuldades de aprendizagem e isso gerou muito expectativa e desejo que fazer algo por eles. (E.13)

Desta forma Freire nos direciona a pensar sobre nossas capacidades com relação ao aprendizado dos alunos da EJA, fortalecendo a ideia de que somos capazes de aprender:

\begin{abstract}
Mulheres e homens, somos os únicos seres que, social e historicamente, nos tornamos capazes de aprender é uma aventura criadora, algo, por isso mesmo, muito mais rico do que meramente repetir a lição dada. Aprender para nós é construir, reconstruir, constatar para mudar, o que não se faz sem abertura ao risco e à aventura do espírito. Creio poder afirmar, na altura destas considerações, que toda prática educativa demanda a existência de sujeitos, um que, ensinando, aprende, outro que, aprendendo, ensina, daí o seu cunho gnosiológico; a existência de objetos, conteúdos a serem ensinados e aprendidos; envolve o uso de métodos, de técnicas, de materiais; implica, em função de seu caráter diretivo, objetivo, sonhos, utopias, ideais. Daí a sua politicidade, qualidade que tem prática educativa de ser política, de não poder ser neutra. (FREIRE, 1996, p.69-70).
\end{abstract}

É preciso que nos aventuremos rumo ao desconhecido, pois somente desta forma nos será possível o enriquecimento do aprendizado e dos benefícios que os conhecimentos adquiridos irão nos proporcionar a cada conquista realizada.

\title{
2. O QUE OS SUJEITOS DA EJA ESPERAM?
}

A prática pedagógica dos estágios mostrou que as narrativas orais dos alunos da EJA estavam repletas de histórias vividas. Ao trabalharmos com projetos as dimensões multiculturais e ambientais foi possível estimular o desenvolvimento da sensibilidade para as questões da realidade dos alunos da EJA e, consequentemente nos despertou para uma postura investigativa, para uma reflexão sobre esses sujeitos e as intervenções pedagógicas necessárias. Desse modo, o estágio realizado por meio de projetos possibilitou aos estagiários a experiência real em todo o processo, o qual foi desde o diagnóstico da realidade da turma, até a ação de intervenção pedagógica. Para Pimenta (2004, p. 229), [...] o "projeto é o elemento mobilizador; é ele que harmoniza o conjunto de ações dos indivíduos com as necessidades do coletivo numa comunidade escolar". Isso nos deu abertura para dentrar nas histórias de vida dos alunos da EJA de modo não invasivo.

Desta forma, a finalidade da prática educativa na EJA pela ação dos estagiários foi de provocar aprendizagem significativa acerca da multiculturalidade e das questões ambientais nos alunos e incentivá-los a narrar de forma oral suas histórias. 
Nas histórias de vida orais dos alunos da EJA, foi possível perceber que voltar a estudar não é uma tarefa tão simples assim. Os sujeitos ao decidirem voltar para sala de aula precisam enfrentar seus próprios "tabus", como a vergonha, pois, não se acham capazes, ou como alguns dizem "já passaram da idade", ou ainda, sentem receio de mudar sua rotina. É muito comum encontrarmos esses tipos de barreiras nos alunos da EJA que tentaram o caminho da escola. Eles precisam fazer algumas mudanças como dedicar tempo ao estudo e isso acaba afetando alguns de seus hábitos e sua vida familiar. Segundo Schwartz (2010, p.67):

\begin{abstract}
Conscientemente, os jovens e adultos analfabetos podem até saber que seria vantajoso essa aprendizagem, mais inconscientemente, desenvolvem mecanismos de defesa para não construí-la por medo do desconhecido, ou por não se sentirem capazes, por exemplo.
\end{abstract}

Após enfrentarem a sala de aula logo aparecem novos desafios na busca pelo conhecimento, sobretudo o desafio de aprender. Vão se inserir em um novo mundo, fazer novas descobertas e encontrar outras maneiras de resolver algumas situações rotineiras que os impedia de um acesso mais fácil ao mundo em que vivem como expressado nas histórias de vida orais a seguir:

Sei que no início vai ser difícil, terei que mudar meus hábitos... tem minha família...coisa e tal... mas tenho que persistir se desejo fazer alguma coisa por mim. (Aluno D)

[...] vejo quanto o estudo é importante para mim. Às vezes, olho para mim mesmo e me pergunto. Será que a culpa foi dos meus pais ou preguiça minha de estudar? Agora chegou a hora, vou até o fim. (Aluno Q)

Eu aprendi não só a ler e escrever, mas também aprendi a me relacionar melhor com as pessoas. Sou uma pessoa nova. É por isso, que aqui eu me sinto bem e me empolgo. Quero crescer e ser capaz como pessoa. (Aluno R)

Sou privilegiada em estudar na EJA, especialmente pelo acolhimento e o carisma e competência dos estagiários que ensinam. (Aluno E)

$\mathrm{Na}$ sala de aula todos se respeitam, tem um pouco de bagunça, mas existe muita amizade. Na hora de aula, quando o professor está passando matéria, eu presto. Se uma pessoa não entende, o estagiário tenta ajudá-lo. (Aluno F)

Durante o estágio, no acompanhamento dos alunos se presenciou muitas histórias de vida orais que nos deram indícios dos caminhos que os conduziram até a escola e que revelaram que a dimensão multicultural estava sendo um entrave na vida deles, como apresentamos nos depoimentos a seguir:

Quando os estagiários nos alertaram que as questões multiculturais e ambientais eram importantes para o nosso desenvolvimento, percebi que o que me afastou da escola foi porque nunca fui aceito por causa de minha sexualidade. (Aluno A)

Sou negra, sofri bulling, deixei a escola. Agora adulta e sem medo, voltei (Aluna G) 
Sou catadora. Pensei que não seria aceita entre meus amigos, mas discutir as questões ambientais me percebi importante no grupo, pois sei do que os estagiários estão falando (Aluna M)

Segundo o aluno "A" o seu objetivo ao ingressar na EJA era para crescer profissionalmente e ter boas oportunidades no mercado de trabalho". Em outro momento tivemos novos relatos como de outros alunos dizendo que: "quero terminar os estudos, para poder entrar na faculdade" (Aluno B). Alguns alunos da EJA, no princípio do estágio são tímidos, mas após alguns encontros passam a interagir com uma grande frequência com os estagiários participando das atividades, originando assim muitas conversa e debates, gerados a partir dos temas e assuntos propostos: Multiculturalidade e Educação Ambiental. Conforme Schwartz (2010, p.64-65):

\begin{abstract}
No dia a dia é possível perceber que apenas querer fazer alguma coisa não é o suficiente para fazê-la. Exemplos para isso não faltam: dieta, parar de fumar, fazer exercícios. Parece que existem razões que a própria razão desconhece. Esta sempre procurou explicar, a si mesma, as ações e pensamentos dos sujeitos. E o que descobre? Descobre que na base de tudo está o prazer que é, de fato, o que move cada sujeito na busca do atendimento às suas necessidades. No caso da aprendizagem da leitura e da escrita, uma possibilidade desse sentimento do prazer seria o de perceber que está aprendendo e, consequentemente, de que é um ser capaz.
\end{abstract}

Percebemos que são inúmeros os objetivos para voltar a estudar, que os levam em busca da realização tanto pessoal como profissional. A aluna "C", entre outros que se fazem presentes na turma, possuía como objetivo maior era ter um diploma como mostramos a seguir:

Quero ter um diploma para mostrar para minha família que consegui terminar o curso. Eles não acreditam muito em mim. (aluna $\mathrm{C}$ )

Quando entrar na faculdade, quero que minha experiência de catadora seja, um exemplo de vida (Aluna M)

Sei ao entrar na faculdade, as coisas vão melhorar para meu lado. Acredito que as discussões sobre raça e étnica podem ser discutidas com mais força. (Aluna $\mathrm{G}$ )

Além de tanta vontade de aprender, o caminho para essa realização tem que ser de acordo com o contexto de cada aluno. A EJA leva esses estudantes a alcançar seus objetivos, trazendo métodos que estão de acordo com a realidade desses sujeitos. O docente precisa buscar métodos para a compreensão maior do grupo, e tentar trabalhar assuntos presentes no dia-a-dia como as dimensões multiculturais e ambientais. Como destaca Schwartz "Embora cada sujeito seja uma singularidade, todos têm características em comuns, bem como os processos de ensino e de aprendizagem. A partir dessas características comuns o professor promoverá as situações de ensino e de aprendizagem. (SCHWARTZ, 2010, p.67).” 
O envolvimento dos alunos com a escola e, principalmente, esse contato afetuoso com o professor é muito importante para que eles permaneçam nas aulas e não desistam de aprender e se envolverem com as questões sociais e políticas. É esse envolvimento mais amplo e satisfatório que os conduz a outros caminhos, ou seja, levam os alunos da EJA e os estagiários do USJ a seguirem em frente e buscarem outros objetivos além daqueles que almejavam quando iniciaram o curso, pois percebem que são cidadãos com direitos e deveres.

A educação segundo a Constituição Federal de 1988, no seu artigo 208, é um direito de todos. Nesse sentido, o Parecer CNE/CEB n ${ }^{\circ}$ 6/2010 resolve no Art. $2^{\circ}$ :

\footnotetext{
Para o melhor desenvolvimento da EJA, cabe a institucionalização de um sistema educacional público de Educação Básica de jovens e adultos, como política pública de Estado e não apenas de governo, assumindo a gestão democrática, contemplando a diversidade de sujeitos aprendizes, proporcionando a conjugação de políticas públicas setoriais e fortalecendo sua vocação como instrumento para a educação ao longo da vida. (BRASIL, 2013, p. 369)
}

Ela proporciona ao sujeito jovem ou adulto possibilidades para que o mesmo tenha condições de mostrar suas habilidades, seu potencial, resgatando sua dignidade e autoestima, provando assim que tem competência, pois este traz consigo muitas experiências que por ele foram vividas fora do contexto escolar.

Apesar da aparente exaustão da temática, esta é uma questão nunca suficientemente problematizada, as discussões sobre currículo abordada nesta modalidade de ensino, ou qualquer nível da educação serão, sempre útil e necessário para pensarmos sobre o currículo, objetivos e finalidades do Ensino Fundamental, voltado para a EJA, destacando a alfabetização.

O processo de alfabetização de jovens e adultos permite que o sujeito tenha condições de superar os desafios cotidianos durante seu tempo de aprendizagem, oportunizando ao mesmo mais condições para desenvolver seu crescimento pessoal e profissional. A busca pelo conhecimento gera expectativas, instigando no sujeito o desejo de superar novos desafios.

Após conhecer um pouco da trajetória de vida dos alunos da EJA e conquistar a confiança dos mesmos, elaboramos um projeto de intervenção que envolveu a multiculturalidade e a educação ambiental, apresentando a possibilidade de uma intervenção mais consistente e dinâmica para a vida deles. A modalidade de ensino EJA não é apenas uma compensação para os alunos que, por diversos motivos, não 
obtiveram sucesso em se alfabetizar, por isso há a necessidade de um planejamento e currículo adequados. Essa perspectiva é claramente explicitada por Thompson (2002, p. 13), quando afirma:

\begin{abstract}
O que é diferente acerca do estudante adulto é a experiência que ele traz para a relação. A experiência modifica, às vezes de maneira sutil e às vezes mais radicalmente, todo o processo educacional; influencia os métodos de ensino, a seleção e o aperfeiçoamento dos mestres e do currículo, podendo até mesmo revelar pontos fracos ou omissões nas disciplinas acadêmicas tradicionais e levar à elaboração de novas áreas de estudo.
\end{abstract}

Ainda em consonância com este pensamento, de experiência de vida, podemos encontrar a seguinte afirmação na proposta curricular apresentada pelo MEC (BRASIL, 2001, p.167).

\begin{abstract}
Jovens e adultos com pouca ou nenhuma escolaridade anterior detêm uma grande quantidade de conhecimentos sobre fenômenos naturais e sobre dinâmica social, econômica, politica e cultural do mundo contemporâneo. Elaboram esses conhecimentos ao longo de suas experiências de vida e de trabalho, tendo já desenvolvido estratégias que orientam suas condutas e hipóteses interpretativas relacionadas aos mais diferentes aspectos da realidade.
\end{abstract}

Nesse sentido, a ambientalização curricular e dimensão multicultural devem explicitar o currículo e as alternativas de estruturação de aprendizagem e desenvolvimento dos alunos da EJA, incluindo a organização do espaço físico-social., constituindo-se numa conjuntura de discussões, debates e fomento de possíveis alternativas. Os conteúdos referenciais definidos para a ambientalização curricular e o tratamento da multiculturalidade assumem papel relevante nas aulas de EJA, uma vez que é basicamente na aprendizagem e no domínio desses conteúdos que se dá a construção e a aquisição de competências. Nessa perspectiva, valorizamos uma concepção de instituição educacional voltada para a construção de uma cidadania crítica, reflexiva, étnica, criativa e ativa, de forma a possibilitar que os/as estudantes consolidem suas bases culturais e ambientais permitindo identificar-se e posicionar-se perante as transformações na vida produtiva e sociopolítica.

Diante do contexto vivido na EJA acerca da complexidade dos cenários multicultural e ambiental percebemos a necessidade de uma práxis que invista nas mudanças de práticas pedagógicas, repensando as lutas e conquistas [...] dos grupos minoritários que chegam à escola no processo de inclusão (MOREIRA; CANDAU, 2003). O que deixamos de interesse no estágio é que o processo de apropriação 
conceitual relativa multiculturalidade e Educação Ambiental apresentaram-se em três etapas interdependentes e complementares: a) fundamentação teórica e produção de material didático; b) observação para diagnosticar e reconhecer o contexto vivido e relatado pelos alunos da EJA; e, c) a intervenção no contexto da sala de aula.

Nas intervenções, então, foi possível perceber os resultados alcançados quando se incorporou a temática ambiental e multicultural no planejamento da prática de ensino em EJA gerando subsídios para a ambientalização curricular nessa modalidade de ensino e o intercâmbio de conhecimentos para formação cidadã e multicultural.

\section{CONSIDERAÇÕES FINAIS}

O estágio na Educação de Jovens e Adultos proporcionou aos estagiários não só uma nova experiência, para ser acrescentada no currículo, mas um novo conhecimento, pois a cada observação e intervenção ficou perceptível que aqueles alunos da EJA teriam muito mais a ensinar do que os estagiários a eles. A partir de cada história de vida relatada por eles, notamos que são sujeitos que talvez não apresentassem muito conhecimento científico, mas em compensação nos mostraram que aprender significa muito mais do que aprender determinado conteúdo, mas que o conhecimento é, também, algo transmitido a partir das multi relações.

Dessa forma, consideramos que ao trabalhar com os sujeitos da EJA, devemos também orientá-los para os conhecimentos e mudanças que estão cada vez mais presentes na sociedade. É importante que nós como professores, abrimos possibilidades de mudança em nossas práticas, para podermos beneficiar os sujeitos que estão presentes na EJA, que buscam formas de estarem inseridos também nas mudanças que acontecem rapidamente na sociedade. Mas não basta só querer é preciso buscar estratégias de mudanças que possam intervir para mudar e a formar sujeitos críticos.

E, nesse sentido, as discussões sobre educação ambiental e multiculturalidade ampliou e significou para todos os envolvidos um desafio para o desenvolvimento pessoal e profissional em que as melhores escolhas podem ser discutidas e retomadas a qualquer tempo deixando de ser somente um ato de obediência à lei. Por isso que durante as discussões emergiram valores como tolerância, generosidade, convivência; respeito mútuo, acolhimento, diferença cuidados com todas as formas de vida integrando na complexidade da vida dos alunos da EJA o meio ambiente e cultural como um caminho necessário para a ambientalização curricular, via reforma do pensamento e da mudança de atitudes. 
Para finalizar, esse artigo, salientamos que no decorrer dessa pesquisa, percebemos que aprender realmente é um processo permanente e contínuo. Porém, as situações vivenciadas, são significadas nas histórias de vida orais e o que direciona os professores pesquisados por meio da reflexão e a tomada de consciência, para que se transformem em experiências significativas em saberes contextualizados. Dessa forma, acreditamos que essa pesquisa não termina aqui, ela se encerra em reticências por algum momento, mas ainda busca outras histórias de vida para serem oralizadas e analisadas nos estágios em EJA.

\section{REFERÊNCIAS}

FREIRE, Paulo. Pedagogia do Oprimido. Rio de Janeiro: Paz e Terra, 2005.

FREIRE, Paulo. Pedagogia da autonomia: Saberes necessários à prática educativa. 33 . ed. São Paulo: Paz e Terra, 1996.

GADOTTI, Moacir. Educação de Jovens e Adultos como Direito Humano. São Paulo: Editora e Livraria Instituto Paulo Freire. 2009.

GALVÃO. Cecília. Narrativas em Educação. In: Ciência e Educação. v.11, n 2, p. 327-345, 2005

LOPES, Selva Paraguassu; SOUSA, Luzia Silva. EJA: Uma educação possível ou mera utopia? [s.n.t.]. Disponível em: $<$ WWW.cereja.org.br/pdf/revista_V/Revista_ SelvaPLopes.pdf > . Acesso em: 02 nov. .2015.

MONTEIRO, F. M. A. Desenvolvimento Profissional da Docência: Uma Experiência de Formação em um Curso de Licenciatura em Pedagogia. Tese de Doutorado. PPGECECH-UFSCAR, 2003.

MIZUKAMI, M. da G. [et al.]. Escola e aprendizagem da docência: processos de investigação e formação. São Carlos, SP: EdUFSCAR, 2002a.

Moreira, A. F. B. e Candau, V. M. (2003). Educação escolar e cultura(s): construindo caminhos. Revista Brasileira de Educação. $n^{\circ}$. 23. Rio de Janeiro, Mar/Ago, p. 156168.

OLIVEIRA, Romualdo P. de (org.). Política educacional: impasses e alternativas. São Paulo: Cortez, 1995.

PIMENTA, Selma Garrido, LIMA, Maria Socorro Lucena. Estágio e Docência. São Paulo: Cortez, 2004.

BRASIL, Educação para jovens e adultos: ensino fundamental: proposta curricular $1^{\circ}$ segmento / - São Paulo: Ação Educativa; Brasília: MEC, 2001.

SCHWARTZ, Suzana. Alfabetização de jovens e adultos: teoria e prática. Petrópolis, RJ: Vozes, 2010.

THOMPSON, E. P. Educação e experiência. In: Thompson, E.P. Os românticos: a Inglaterra na era revolucionária. Rio de Janeiro: Civilização Brasileira, 2002. p. 11-47.

1. Dra em Educação pela PUCRS. Professora do USJ e Pós Doutoranda pela UNIPLAC.

2. Dra pela Unisinos. Professora do USJ 